\title{
In Vitro Evaluation of Remineralizing Effect of Nano-Carbonate Apatite on Demineralized Stripped Enamel Surfaces
}

\author{
Shaimaa A. Negem ${ }^{1^{*}}$, Laila S. Ghali², Wael M. Abd Al Khalek ${ }^{1}$ \\ 'Department of Pediatric and Preventive Dentistry and Dental Public Health, Faculty of Dentistry, Suez Canal \\ University. ${ }^{2}$ Departmet of Oral Biology, Faculty of Oral and Dental Medicine, Cairo University
}

\begin{abstract}
Aim: to evaluate the changes of surface hardness and remineralizing effect of nano-carbonate apatite on demineralized stripped enamel surfaces by SEM and micro-hardness examination. Materials and Methods: Forty-five extracted premolars received proximal stripping using diamond coated metal hand-held strip. Each tooth was sectioned by means of a low-speed air and watercooled diamond disc along its major axis into mesial and distal halves i.e. obtaining 90 tooth sections (30 unstripped \&60 stripped) and divided into 3 groups: Group A (A1 15 unstripped; A2 15 stripped) served as control. Group B (B1 15 unstripped; B2 15 stripped) specimens were placed in lactic acid for $1 \mathrm{~h}$ three times a day with $2 \mathrm{~h}$ preservation in artificial saliva in between for 7 days. Group C ( $C_{1} 15$ unstripped; C215 stripped) specimens were received same treatment as group B then treated with remineralizing agent (APF for C1\& n-CAP for C2) immediately after each demineralizing bath. Results: SEM results showed greater demineralization in subgroup B2 compared to $B 1$, while it revealed greater remineralization in subgroup $C_{2}$ ( $n$-CAP) compared to $C_{1}$ (APF). Surface microhardness examination results using Mann-Whitney test showed significant decrease in SMH of group B2 compared with (A). SubgroupC1 (APF) showed increase in SMH compared with subgroup $B 2$ with no significant, and decrease compared with group (A). While there was no significant in SMH of subgroup $C_{2}$ when compared with group $(A)$, however there was highly significant increase in SMH of subgroup (C2) compared with those of subgroup B2 followed by subgroup $\mathrm{C}_{1}$. Conclusion: N-CAP could be considered as a valuable non-fluoride alternative to fluoride containing formulations used for suppressing demineralization and enhancing remineralization of enamel. It can be considered as a potential caries preventive agent showing promise for the recovery of damaged enamel structures.
\end{abstract}

Keywords: premolars, proximal stripping, Surface microhardness

\section{Introduction}

Prevention of dental caries and the remineralization of enamel subsurface lesions before restorative intervention are a major challenge and goal of modern dentistry ${ }^{(1,2)}$. Although a physiological equilibrium exists between remineralization and demineralization of the dental hard tissues in the oral cavity, an increase in organic acids derived from dental plaque or an acidic dietary lead to a change of this equilibrium inducing demineralization of the tooth surface ${ }^{(3,4)}$. If the demineralization effect overcomes the 
self-regulated remineralization, excessive loss of mineral content from the dental hard tissues may occur jeopardizing the integrity of the teeth(5). In biogeochemistry, remineralization refers to the transformation of organic molecules to inorganic forms, typically mediated by biological activity. Usually remineralisation relates to organic and inorganic molecules involving biologically important elements such as carbon dioxide, nitrate (nitric acid) and phosphate (phosphoric acid) ${ }^{(6)}$. Hydroxyapatite [HAP, Ca10 (PO4)6(OH) 2] is an attractive material for bone or dental implants owing to its biocompatible and bioactive properties $(7,8)$. The application of HAP to the biomimetic repair of damaged enamel directly has attracted considerable great attention in dental research because of its chemical and structural similarity to tooth minerals. Moreover, HAP can have new physical properties if it can be made similar to the enamel crystal size by nano technology (9). Nano materials can adhere easily to a rough surface and have bioactive and biocompatible properties because the surface area and proportion of atomicity increase with decreasing particle size ${ }^{(9,}$ 10). The remineralization effect is increased if the particle size of HAP can be reduced to the nanometric range ${ }^{(11,12)}$. Fluoride is the cornerstone of the noninvasive management of non-cavitated caries lesions, but the ability of the ion to promote net remineralization is limited by the availability

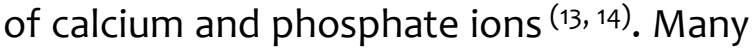
of researches have demonstrated that $10 \%$ nano-hydroxyapaptite (n-HAP) has a similar effect on initial caries lesion to fluoride $^{(15,16)}$ and HAP has an excellent ability to biomimetically repair the enamel subjected to acid attack ${ }^{(9)}$. Nano -carbonate apatite (n-CAP) carbonate apatite has a similar structure to the inorganic component of teeth and bone so it can bond chemically to the surface of natural enamel, producing a persistent coating and filling scratches and pits (17). In addition, n-CAP is most effective in occluding the dentinal tubules than other desensitizing dentifrices, n-CAP was expected to recover damaged enamel surface avoiding the most probably health dangerous fluoride effects ${ }^{(18)}$

\section{Materials and Methods}

Forty-five premolar teeth extracted for orthodontic reasons from children between 8-12 years of age, selected from the outpatient clinic of Pedodontic, and Orthodontic Departments, Pediatric Dentistry Clinic, Faculty of Dentistry, Suez Canal University, Ismailia city, Egypt Were used in this investigation. Teeth free from any macroscopic defects were chosen and randomly classified into two sets of teeth (sets I and II); Set l: consisted of 30 teeth, they were proximally stripped on their mesial surfaces while distal surfaces remained intact to serve as controls. Set II: consisted of 15 teeth; they were stripped on both mesial \&distal surfaces. Then each tooth was sectioned buccolingually separating it into mesial and distal halves i.e. obtaining 90 teeth sections (30 unstripped and 60 stripped). Teeth sections were divided into three groups $A, B$ and $C$. Then each group was subdivided into 2 subgroups; Group A, consisted of 30 tooth sections incubated in artificial saliva which was exchanged every day for 7 days and served as controls. (Subgroup A1: 15 unstripped specimens. SubgroupA2: 15 stripped specimens). Group $B$, consisted of 30 tooth sections which subjected to a $0.1 \mathrm{M}$ lactic acid adjusted to $\mathrm{pH}$ (4.4) for 1 hour followed by 2 hours preservation in artificial saliva in between three times a day for 7 days. (Subgroup B1:15 unstripped specimens. Subgroup B2: 15 stripped specimens). Group C, consisted of 30 tooth sections which received the same 
treatment as those of group $B$, then teeth specimens were treated with a remineralizing agent for three applications daily immediately after each time tooth sections were subjected to lactic acid for 7 days. (Subgroup C1: 15 stripped specimens treated with APF*, Subgroup C2: 15 stripped specimens treated with n-CAP). At the end of the experiment specimens from each group ( $A, B$ and $C$ ) were carefully dehydrated and gold coated to be examined by scanning electron microscope. Five tooth specimens from each group were serially polished to be used to measure enamel microhardness. All data were recorded and statistically analyzed using Kruskal Wallis test then, Mann-Whitney test in order to clarify if there is significant difference or interaction between groups.

*TOPEX ${ }^{\circledR}$, Topical A.P.F.GEL, Acidulated Phosphate Fluoride containing $1.23 \%$ fluoride ion ( $\mathrm{pH}$ 3.5), Sultan Healthcare, USA.

\section{Results}

Results of Scanning Electron Microscopic (SEM) examination: The SE photomicrograph of Subgroup A1 (non-treated Subgroup) showed no specific structural defects. Bands of prism end depressions most commonly alternate with smooth areas representing the incremental lines of Retzius as showed in Fig (1). Scanning electron microscopic examination of enamel surfaces of Subgroup A2 showed alterations, manifested as roughened and grooved enamel surfaces Fig (2). Scanning electron microscopic examination of enamel surfaces of Subgroup B1 revealed marked surface roughness characterized by a typically etched pattern of enamel with a lot of irregularities, seen as pores, pittings, craters of various sizes and depth Fig (3). The SEM examination of enamel surfaces of subgroup B2 showed marked surface alterations with a punchboard or honeycombed pattern Fig (4). Scanning electron microscopic examination of subgroup $\mathrm{C}_{1}$ revealed improvements of the enamel ultrastructure with the application of APF. The specimens manifested a smoother enamel surface with decreased number, size and depth of previously formed pores. Crystal like structures was found on the enamel surface which may probably indicate precipitation of minerals Fig (5). The SEM examination of subgroup C2 showed that the treatment of demineralized enamel surfaces with n-CAP revealed enamel surface with much lesser pitting and porosities both in size and depth compared to APF subgroup Fig (6) and appeared with a lot of new crystal formation denoting deposition of minerals Fig (7).

Microhardness results: Statistical analysis of microhardness measurements showed no significant difference between SubgroupA1and SubgroupA2. There was significant decrease in the enamel microhardness of SubgroupB2, while Subgroup B1 showed decrease with no significant.

\section{Discussion}

Enamel is the hardest and most mineralized tissue of human body. It is structured to resist to mechanical injuries, abrasion, and chemical attack. Differently from all the other mineralized tissues, it lacks proteins even if they are essential to its formation. Matrix proteins are cleaved by proteinases secreted by the ameloblasts during tooth formation; hence, the matrix proteins of enamel are not incorporated into enamel prisms(19). Degradation and resumption of enamel matrix proteins is the reason why enamel prisms, once formed, cannot be remodeled. After enamel prism formation, only the amount of hydroxyapatite within the prisms may decrease in consequence of chemical changes into the oral environment ${ }^{(17)}$. SE photomicrograph 
of stripped enamel surfaces of subgroup A2 showed rougher enamel surfaces with many grooves and furrows compared with SE photomicrograph of unstripped enamel surfaces of subgroup A1, (Fig. 2) and (Fig. 1) respectively, these findings may be attribu- ted to effect of orthodontic cases that were treated by interdental stripping on enamel morphology. And polishing should decrease but not eliminate these enamel irregularities which are still clearly visible at SEM observation after stripping.

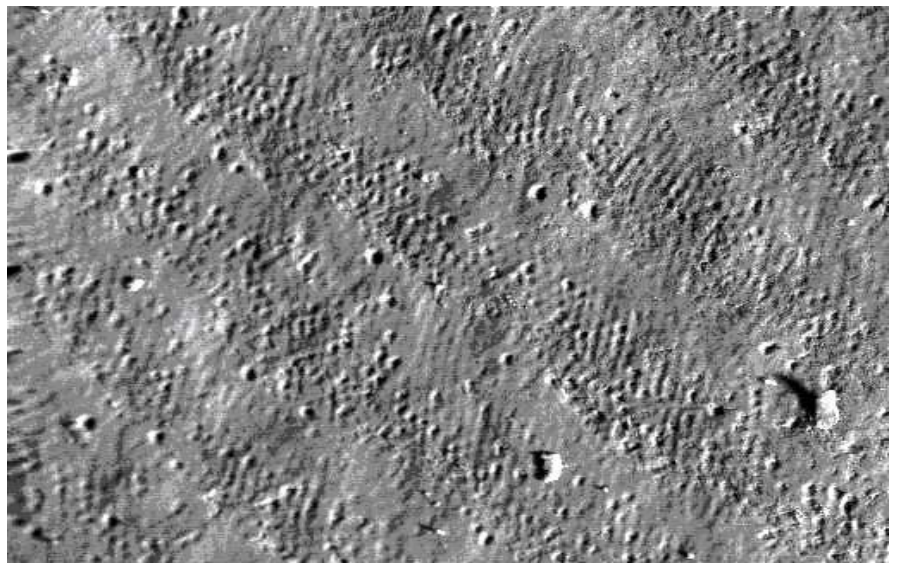

Figure (1): SE photo micrograph of normal enamel showing bands of prism ends (a) alternating with smooth areas representing incremental lines of Retzius (b). (orig.mag.250)

These results are in agreement with previous reports ${ }^{(20-22)}$, and are in agreement with Sheridan JJ, $1989^{(23)}$, who reported that under these circumstances, plaque accumulation could be expected even after intensive hygiene, including flossing which cannot dislodge plaque from artificial grooves. So far, it had been accepted that the roughness of intraoral surfaces might favour initial bacterial adhesion and plaque retention. The SEM observations of unstripped enamel surfaces of subgroup B1 and demineralized by $0.1 \mathrm{M}$ lactic acid showed artificially induced caries like lesions that characterized by a typically etched pattern of enamel with a lot of irregularities and porosities (Fig. 3). These results are in agreement with the findings of Giulio et al ${ }^{(24)}$ who found early pattern of demineralization with interprismatic tissue dissolution when unstripped enamel surfaces exposed to this acid and examined by SEM. This may be due to acid attack that is one of the major causes of enamel hydroxyapatite loss. It may occur even in young age because of plaque metabolism or simply due to food and beverage intakes. These result in agreement with previous studies $^{(25,26)}$. The SEM analysis carried out after exposure of stripped enamel surfaces of subgroup B2 to lactic acid and the results showed that stripped enamel surfaces achieved greater demineralization compared to unstripped subgroup B1. Acid exposure of unstripped enamel surfaces subgroup B1 produced an early pattern of demineralization with evidence of interprismatic tissue loss (Fig.3). revealed greater enamel dissolution, resembling a more advanced stage of demineralization in which the integrity of the enamel prism cores was severely affected characterized by appearance like punchboard or honeycomb (Fig. 4). abraded areas of enamel surfaces may favor the adherence of bacterial plaque and may offer little resistance to breakdown and appears to be more susceptible to demineralization. Thus, hygiene instructions, including interproximal plaque control and prophylactic measures 

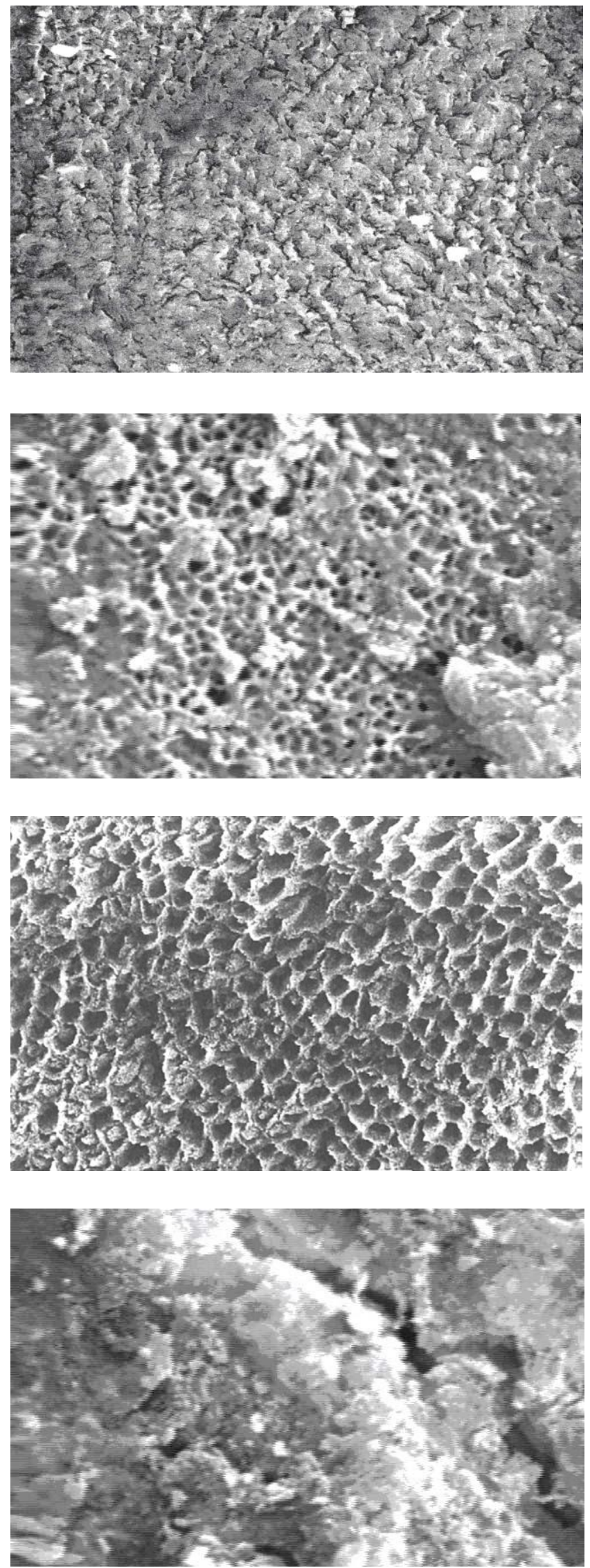

Figure 2: $\mathrm{SE}$ photo micrograph of stripped enamel (Subgroup A2) showing roughened enamel surface. (orig. mag. 2000)

Figure 3: SE photo micrograph of enamel of demineralized specimens (Subgroup B1) showing dissolution of enamel prism cores with a lot of micro pittings, micro pores and marked surface roughness. (orig.mag. 5000)

Figure 4: SE photo micrograph of stripped enamel exposed to lactic acid (SubgroupB2) showing honeycomb like structure. (orig. mag. 1000)

Figure 5: SE photo micrograph of stripped enamel of sub-group $\mathrm{C}_{1}$ showing a lot of crystals like structures on the surface of enamel (orig. mag. 5000). 
must be done to prevent undesirable sequelae of the procedure. On the contrary, morphological characteristics of stripped samples (subgroup B2) These findings agree with Giulio et al(24), who found that the alterations and the These findings could may explained according to Twesme et $\mathrm{al}^{(27)}$ who hypothesized that enamel ir- regularities caused by the stripping procedure may determine a greater surface area exposed to the acid solution and, consequently, an increased enamel dissolution compared to unstripped surfaces. Furthermore, removal of the outer layer of enamel by stripping leads to the exposure of enamel less resistant to dissolution.

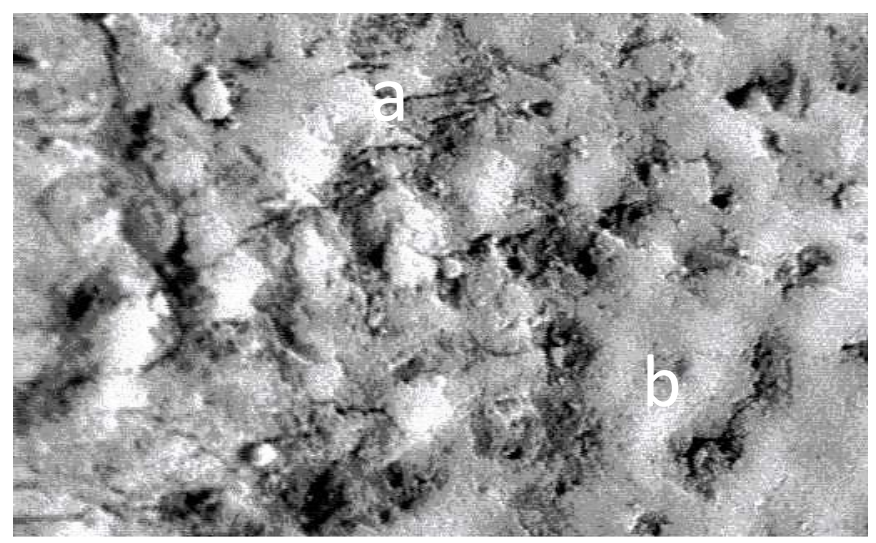

Figure 6: SE photo micrograph of enamel from specimen dem. remineralized with n-CAP (sub-group C2) showing enamel surface with much lesser pitting and porosities compared to APF group (orig. mag. 2500)

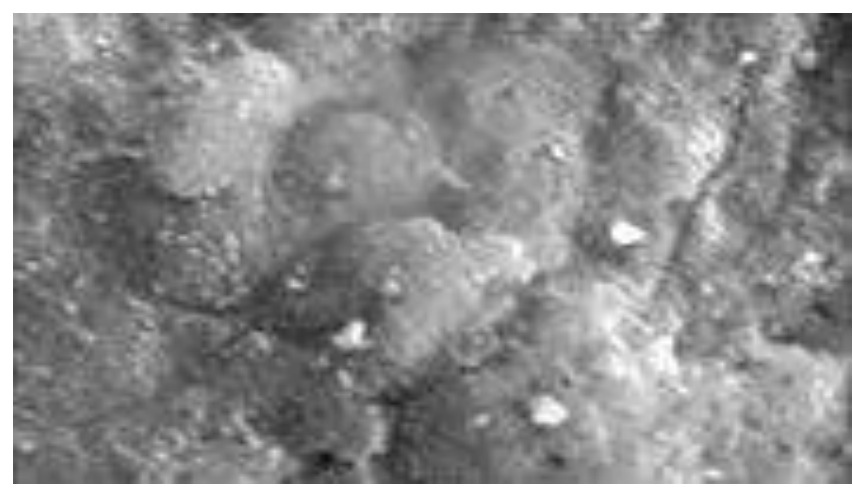

Figure 7: SE photo micrograph of enamel from specimen dem.remineralized with n-cap (subgroup C2) showing more or less normal enamel surface. (orig. mag. 4000)

In this study, an in vitro enamel surface remineralization by brushing with paste containing either fluoride or n-CAP microclusters for 10 minute had been carried out. SEM images after treatment with n-CAP or fluoride paste. This investigation is in agreement with Roveri et al ${ }^{(17)}$ who underlined by it the possibility to obtain an enamel remineralization through the formation of a surface apatite coating which covers the enamel structure avoiding the most probably health dangerous fluoride effects, to contrast the mechanical abrasion and acid attacks to which tooth enamel is exposed. Concerning the fluoride treatment, we found that APF improved the enamel ultrastructure (Fig. 5), these results of SEM agreed with previous investigations ${ }^{(28-30)}$, who reported that caries lesion progression was inhibited by a fluoride source, in a $\mathrm{pH}$-cycling model. This may be due to the reaction product of highly concentrated fluoride preparations $\mathrm{CaF}_{2}$, which is responsible for cariostatic efficacy. However Zahradnik et al(31) reported that no discernible differences exist between the control and APF treated samples after 3 days of exposure to the lactate buffer; however, after 5 days incubation with $S$. mutans strain, a significant reduction in mineral loss was observed with the APF treated samples. This may be due to the difference in the study design using chemical system. In this study treatment of 
stripped demineralized enamel surface with $n$-CAP resulted in increased remineralization, where appeared with much lesser pitting and porosities both in size and depth compared to APF group and regained its normal ultrastructures with a lot of new crystal formation denoting deposition of minerals to the enamel surface whose morphology was detected by SEM analysis (Fig. 6, 7). These results may be attributed to size of n-CAP crystal that was $100 \mathrm{~nm}$ demonstrated by TEM. These find ings are in agreement with Linhart et al, $2001^{(32)}$ who reported that if nano-sized CAP attaches to the enamel surface or penetrates between the enamel rods, n-CAP will recover damaged enamel or block up defects. In addition, n-CAP was shown to be amorphous. Amorphous CAP has higher solubility and similar to tooth structure Therefore, amorphous n-CAP was expected to dissolve in the oral cavity and redeposit on the damaged region by providing calcium or phosphate.

Table 1. Multiple comparisons between micro-hardness of A subgroups ( $A 1$ \&

$\mathrm{A} 2$ ) and other tested subgroups

\begin{tabular}{|c|c|c|c|c|c|}
\hline \multirow{2}{*}{ Subgroup } & \multirow{2}{*}{$\begin{array}{c}\text { Other } \\
\text { subgroups }\end{array}$} & \multirow{2}{*}{$\begin{array}{c}\text { Mean } \\
\text { Difference }\end{array}$} & \multicolumn{2}{|c|}{$95 \%$ Confidence Interval } & \multirow{2}{*}{$\mathrm{p}$-value } \\
\hline & & & $\begin{array}{l}\text { Lower } \\
\text { Bound }\end{array}$ & $\begin{array}{l}\text { Upper } \\
\text { Bound }\end{array}$ & \\
\hline \multirow[t]{5}{*}{$A 1$} & $A_{2}$ & 41.56 & -78.40 & 161.51 & 0.289 \\
\hline & B1 & 128.74 & 0.50 & 256.98 & 0.050 \\
\hline & B2 & 142.81 & 22.86 & 262.77 & $0.034^{*}$ \\
\hline & $\mathrm{C} 1$ & 85.91 & -22.47 & 194.30 & 0.053 \\
\hline & $\mathrm{C} 2$ & 6.86 & -101.52 & 115.24 & 0.569 \\
\hline \multirow[t]{5}{*}{$\mathrm{A} 2$} & $\mathrm{~A}_{1}$ & -41.56 & -161.51 & 78.40 & 0.289 \\
\hline & B1 & 87.19 & -32.77 & 207.14 & 0.157 \\
\hline & $\mathrm{B} 2$ & 101.26 & -9.80 & 212.31 & $0.043^{*}$ \\
\hline & $\mathrm{C}_{1}$ & 44.36 & -54.09 & 142.80 & 0.186 \\
\hline & $\mathrm{C}_{2}$ & -34.70 & -133.14 & 63.74 & 0.345 \\
\hline
\end{tabular}

${ }^{*}=$ Mean difference is statistically significant at $p<0.05$, using Mann-Whitney test.

So, synthetic carbonate-hydroxyapatite biomimetic nanocrystals ( $\mathrm{n}$-CAP) had been chemical-physical characterized and investigated regarding the possibility to obtain an in vitro remineralization of the altered enamel surfaces, and these findings was obtained by Roveri et al ${ }^{(17)}$ who reported that the treatment of demineralized enamel only for 10 minutes, by $n-C A P$, induces a consistent enamel remineralization through the formation of a surface carbonate-hydroxyapatite coating. This coating is due to the chemical bond of the synthetic n-cap for composition, structure, size, and morphology on the surface prismatic hydroxyapatite enamel. The application of n-CAP 100nm sized produces the formation of a homogeneous coating which hides interprismatic and prismatic enamel structures when examined with SEM. And in this study, the mean enamel microhardness values of group $(A)$ did not show significant differences between the two subgroups(A1, A2).This finding suggests that the tested stripping method, (enamel stripping with diamond-coated metal hand-held Strips),although it altered the surface of the enamel significantly by 
producing furrows and grooves it preserved the hardness of intact enamel surfaces. Therefore, stripped enamel with dia mond-coated metal hand-held Strips can be used safely, from the microhardness point of view (table1).

Table 2: Multiple comparisons between micro-hardness of B subgroups (B1 \& B2) and other tested subgroups

\begin{tabular}{|c|c|c|c|c|c|}
\hline \multirow[b]{2}{*}{ Subgroup } & \multirow{2}{*}{$\begin{array}{c}\text { Other } \\
\text { subgroups }\end{array}$} & \multirow{2}{*}{$\begin{array}{c}\text { Mean } \\
\text { Difference }\end{array}$} & \multicolumn{2}{|c|}{ 95\% Confidence Interval } & \multirow[b]{2}{*}{$\mathrm{p}$-value } \\
\hline & & & $\begin{array}{l}\text { Lower } \\
\text { Bound }\end{array}$ & $\begin{array}{l}\text { Upper } \\
\text { Bound }\end{array}$ & \\
\hline \multirow[t]{5}{*}{ B1 } & $\mathrm{A}_{1}$ & -128.74 & -256.98 & -0.50 & 0.050 \\
\hline & $\mathrm{A}_{2}$ & -87.19 & -207.14 & 32.77 & 0.157 \\
\hline & $\mathrm{B} 2$ & 14.07 & -105.89 & 134.03 & 0.724 \\
\hline & $\mathrm{C}_{1}$ & -42.83 & -151.21 & 65.55 & 0.210 \\
\hline & $\mathrm{C} 2$ & -121.89 & -230.27 & -13.50 & $0.017^{*}$ \\
\hline \multirow[t]{5}{*}{ B2 } & $\mathrm{A} 1$ & -142.81 & -262.77 & -22.86 & $0.034^{*}$ \\
\hline & $\mathrm{A}_{2}$ & -101.26 & -212.31 & 9.80 & $0.043^{*}$ \\
\hline & B1 & -14.07 & -134.03 & 105.89 & 0.724 \\
\hline & $\mathrm{C} 1$ & -56.90 & -155.34 & 41.54 & 0.059 \\
\hline & $\mathrm{C} 2$ & -135.96 & -234.40 & -37.51 & $0.008^{*}$ \\
\hline
\end{tabular}

Table 3. Multiple comparisons between microhardness of $C$ subgroups $\left(C_{1} \& C_{2}\right)$ and other tested subgroups

\begin{tabular}{|c|c|c|c|c|c|}
\hline \multirow[b]{2}{*}{ Subgroup } & \multirow[b]{2}{*}{$\begin{array}{c}\text { Other } \\
\text { subgroups }\end{array}$} & \multirow[b]{2}{*}{$\begin{array}{c}\text { Mean } \\
\text { Difference }\end{array}$} & \multicolumn{2}{|c|}{$95 \%$ Confidence Interval } & \multirow[b]{2}{*}{$\mathrm{p}$-value } \\
\hline & & & $\begin{array}{l}\text { Lower } \\
\text { Bound }\end{array}$ & $\begin{array}{l}\text { Upper } \\
\text { Bound }\end{array}$ & \\
\hline \multirow[t]{5}{*}{$\mathrm{C}_{1}$} & A1 & -85.91 & $-194 \cdot 30$ & 22.47 & 0.053 \\
\hline & $\mathrm{A} 2$ & $-44 \cdot 36$ & -142.80 & 54.09 & 0.186 \\
\hline & B1 & 42.83 & -65.55 & 151.21 & 0.210 \\
\hline & $\mathrm{B} 2$ & 56.90 & -41.54 & 155.34 & 0.059 \\
\hline & $\mathrm{C} 2$ & -79.06 & -163.01 & 4.89 & $0.009^{*}$ \\
\hline \multirow[t]{5}{*}{$\mathrm{C}_{2}$} & A1 & -6.86 & -115.24 & 101.52 & 0.569 \\
\hline & $\mathrm{A} 2$ & 34.70 & -63.74 & 133.14 & 0.345 \\
\hline & B1 & 121.89 & 13.50 & 230.27 & $0.017^{*}$ \\
\hline & B2 & 135.96 & 37.51 & 234.40 & $0.008^{*}$ \\
\hline & $\mathrm{C}_{1}$ & 79.06 & -4.89 & 163.01 & $0.009^{*}$ \\
\hline
\end{tabular}

*. Mean difference is statistically significant at $p<0.05$, using Mann-Whitney test

This result was supported by the result of Arman et $\mathrm{al}^{(21)}$. The results of the present study revealed that the microhardness of enamel decreased when unstripped enamel was demineralized. This result is in accordance with findings of others(33-35). who reported marked decrease in microhardness of enamel after exposure to demineralizing solution. But this decrease was not significant (table 2); this result may be due to remineralization effect of artificial saliva. This finding is consistent with the result of several studies showed that artificial saliva containing potassium chloride, magnesium chloride, calcium chloride and dipotassium hydrogen phosphate can reharden acid-softened enamel $(36,37)$. The significant decrease in enamel microhardness when stripped enamel was demineralized resulted in these investigations may be due to increasing the surface area exposed to the acid solution which increase enamel dissolution and consequently decreased enamel microhardness compared 
with unstripped enamel( ${ }^{(24,27)}$. There was no significant improvement in surface microhardness of enamel (SMH) in the specimens treated with acidulated phosphate fluoride gel (APF) when compared to stripped demineralized. These results are in agreement with those of paes Leme et $\mathrm{al}^{(38)}$ who found that APF+ Placebo nonfluoridated dentifrice (PD) treatment was not more efficient than (PD) in increasing enamel hardness and an additive effect of $\mathrm{APF}+$ Fluoridated dentifrice (FD), 1,100 ppm F was not observed over PD alone.. On the other hand these results opposed the results of Lata et al(35), Eronat et al(39), Delbem and Cury(40). This result could be due to the difference in application time of APF during periods of acid challenge $(\mathrm{pH}$ cycling) and differences in study design. And by evidence of high significant difference of surface hardness between enamel treated with n-CAP and treated with APF (table 3). This finding is in accordance with those of Roveri et al(17). Finding may be due to, with repeated APF treatments, in depth remineralization is prevented by the reactivity of a surface coating formed during the experiment. Most likely, processes such as calcium fluoride precipitation and phosphate adsorption on calcium fluoride, particles predominate. Therefore, inward transport of ions deep into the underlying enamel does not occur to any great extent. This in agreement with Bodde et al(41), while documented n-CAP coating formation which is less crystalline than enamel natural apatite represents an enamel repair process corresponding to an apatite deposition inside the demineralized area of enamel surface owing to its nano-sized crystals and may be considered an innovative approach to contrast enamel demineralization, and this may approve the result of no significant decrease of enamel microhardness that was less than control. This finding is in agreement with others $^{(17,42)}$ who reported the high efficiency of $n$-CAP in rehardening the enamel surface and increasing the hardness of the caries lesions. Also, these findings explain the result of highly significant increase in enamel microhardness of treated stripped demineralized samples with n-CAP compared to stripped demineralized samples not treated with it and significant increase in enamel hardness compared to unstripped demineralized surfaces not exposed to it.

\section{Conclusion}

Based on the scanning electron microscope and microhardness findings, we conclude that: i) Stripping of enamel resulted in roughened and grooved enamel surfaces. However, it didn't affect enamel microhardness. ii) Removal of surface layer and surface roughness due to stripping of enamel ultimately lead to increased demineralization of enamel. iii) Application of APF on stripped enamel surface minimized demineralization caused by lactic acid. And although remineralization was evident enamel microhardness was still affected. iv) Topical application of n-CAP showed higher remineralization compared to APF, which may be considered to have a highly protective effect against demineralization of stripped enamel. v) N-CAP could be considered as a valuable non-fluoride alternative to fluoride containing formulations used for suppressing demineralization and enhancing remineralization of enamel. It can be considered as a potential caries preventive agent showing promise for the recovery of damaged enamel structures.

\section{References}

1. Biesbrock AR, Gerlach RW, Bollmer BW, Faller RV, Jacobs SA, Bartizek RD. Relative anti-caries efficacy of 1100, 1700, 2200 , and $2800 \mathrm{ppm}$ fluoride ion in a so- 
dium fluoride dentifrice over 1 year. Community Dent Oral Epidemiol. 2001; 29(5):382-9.

2. Marinho VC, Higgins JP, Logan S, Sheiham A. Fluoride mouthrinses for preventing dental caries in children and adolescents. Cochrane Database Syst Rev. 2003; 3: CD 002284.

3. Vollenweider M, Brunner TJ, Knecht S, et al. Remineralization of human dentin using ultrafine bioactive glass particles. Acta Biomater. 2007; 3(6):936-43.

4. Narongdej T, Sakoolnamarka R, Boonroung $T$. The effectiveness of a calcium sodium phosphosilicate desensitizer in reducing cervical dentin hypersensitivity: a pilot study. J Am Dent Assoc. 2010; 141(8): 995-9.

5. Vollenweider M, Brunner TJ, Knecht S, et al. Remineralization of human dentin using ultrafine bioactive glass particles. Acta Biomater. 2007; 3(6):936-43.

6. Gruber N, Sarmiento JL. Ocean Biogeochemical Dynamics. Princeton University Press, Princeton, New Jersey, USA; 2006;5:166-9.

7. LeGeros RZ. Calcium phosphate materials in restorative dentistry: a review. Adv Dent Res. 1988; 2(1):164-80.

8. Sun L, Berndt CC, Gross KA, Kucuk A. Material fundamentals and clinical performance of plasma-sprayed hydroxyapatite coatings: a review. J Biomed Mater Res. 2001; 58(5):570-92.

9. Li L, Pan HH, Tao JH, Xu XR, Mao CY\& Gu $\mathrm{XH}$ : Repair of enamel by using hydroxyapatite nanoparticles as the building blocks. J. Mater. Chem; 18:4079-84.

10. Kaehler T. Nanotechnology: basic concepts and definitions. Clin Chem. 1994; 40(9):1797-9.

11. Webster TJ, Ergun C, Doremus RH, Siegel RW, Bizios R. Specific proteins mediate enhanced osteoblast adhesion on nanophase ceramics. J Biomed Mater Res. 2000; 51(3):475-83.

12. Lv K, Zhang J, Meng X\& Li X: Remineralization effect of the nano-HA toothpaste on artificial caries. Mater. sci. Eng; 3302:267-70, 2007.not found
13. Vogel GL, Schumacher GE, Chow LC, Takagi $S$, Carey $C M$. Ca pre-rinse greatly increases plaque and plaque fluid F. J Dent Res. 2008; 87(5):466-9.

14. Cochrane NJ, Cai F, Huq NL, Burrow MF, Reynolds EC. New approaches to enhanced remineralization of tooth enamel. J Dent Res. 2010; 89(11):1187-97.

15. Huang S, Chen JC, Hsu CW, Chang WH. Effects of nano calcium carbonate and nano calcium citrate on toxicity in ICR mice and on bone mineral density in an ovariectomized mice model. Nanotechnology 2009; 20(37): 375102.

16. Tschoppe P, Zandim DL, Martus P, Kielbassa AM. Enamel and dentine remineralization by nano-hydroxyapatite toothpastes. J Dent. 2011; 39(6):430-7.

17. Roveri N, Palazzo B, lafisco M. The role of biomimetism in developing nanostructured inorganic matrices for drug delivery. Expert Opin Drug Deliv. 2008; 5(8):861-77.

18. Lee SY, Kwon HK, Kim BI. Effect of dentinal tubule occlusion by dentifrice containing nano-carbonate apatite. J Oral Rehabil. 2008; 35(11):847-53.

19. Simmer JP, Fincham AG. Molecular mechanisms of dental enamel formation. Crit Rev Oral Biol Med. 1995; 6(2): 84108.

20. Piacentini C, Sfondrini G. A scanning electron microscopy comparison of enamel polishing methods after air-rotor stripping. Am J Orthod Dentofacial Orthop. 1996; 109(1):57-63.

21. Arman A, Cehreli SB, Ozel E, Arhun N , Cetinsahin A, Soyman M. Qualitative and quantitative evaluation of enamel after various stripping methods. Am J Orthod Dentofacial Orthop. 2006; 130(2): 131.e714.

22. Zachrisson BU, Nyoygaard L, Mobarak K. Dental health assessed more than 10 years after interproximal enamel reduction of mandibular anterior teeth. Am J Orthod Dentofacial Orthop. 2007; 131(2):162-9.

23. Sheridan JJ, Ledoux PM. Air-rotor stripping and proximal sealants. an SEM evaluation. J Clin Orthod. 1989; 23(12):790-4. 
24. Giulio AB, Matteo Z, Serena IP, Silvia $M$, Luigi $C$. In vitro evaluation of casein phosphopeptide-amorphous calcium phosphate (CCP-ACP) effect on stripped enamel surfaces. A SEM investigation. J Dent. 2009; 37(3):228-32.

25. Al-Dlaigan $\mathrm{YH}$, Shaw L, Smith A. Dental erosion in a group of British 14-year-old, school children part I: prevalence and influence of differing socioeconomic backgrounds. Br Dent J. 2001; 190(3):145-9.

26. Dugmore $C R$, Rock WP. The prevalence of tooth erosion in 12-year-old children. Br Dent J. 2004; 196(5): 279-82.

27. Twesme DA, Firestone AR, Heaven TJ, Feagin FF, Jacobson A. Air-rotor stripping and enamel demineralization in vitro. Am J Orthod Dentofacial Orthop. 1994; 105(2):142-52.

28. Steiner-Oliveira C, Rodrigues LK, Lima EB, Nobre dos Santos M. Effect of $\mathrm{CO} 2$ laser combined with fluoridated products on the inhibition of enamel demineralization. J Contemp Dent Pract. 2008; 9(2): 113-21.

29. Tenuta LM, Cerezetti RV, Del Bel Cury AA, Tabchoury CP, Cury JA. Fluoride release from $\mathrm{CaF} 2$ and enamel demineralization. J Dent Res. 2008; 87(11):1032-6.

30. Souza-Gabriel AE, Colucci V, Turssi CP, Serra MC, Corona SA. Microhardness and SEM after CO (2) Laser Irradiation or Fluoride Treatment in Human and Bovine Enamel. Microsc. Res Tech.2010; 73(11):1030-5.

31. Zahradnik RT, Propas D, Moreno EC. Effect of Fluoride Topical Solutions on Enamel Demineralization by Lactate Buffers and Streptococcus mutans in vitro. J Dent Res. 1978; 57(9-10):940-6.

32. Linhart W, Peters F, Lehmann W, et al. Biologically and chemically optimized composites of carbonated apatite and polyglycolide as bone substitution materials. J Biomed Mater Res.2001; 54(2):162-71.

33. Delbem AC, Brighenti FL, Vieira AE, Cury JA. In vitro comparison of the cariostatic effect between topical applications of fluoride gels and fluoride toothpaste. J Appl Oral Sci. 2004; 12(2):121-6.
34. Jardim JJ, Pagot MA, Maltz H: Artificial enamel dental caries treated with different topical fluoride regimes: An in-situ study, J. Dent. 2008; 36:396-401.

35. Lata S, Varghese NO, Varughese JM. Remineralization potential of fluoride and amorphous calcium phosphate-casein phospho peptide on enamel lesions: An in vitro comparative evaluation. J Conserv Dent. 2010; 13(1):42-6.

36. Devlin H, Bassiouny MA, Boston D. Hardness of enamel exposed to Coca- Cola and artificial saliva. J Oral Rehabil 2006; 33(1):26-30.

37. Lussi A, Megert B, Eggenberger D, Jaeggi T. Impact of different toothpastes on the prevention of erosion. Caries Res. 2008; 42(1):62-7.

38. Paes Leme AF, Tabchoury CP, Zero DT, Cury JA. Effect of fluoridated dentifrice and acidulated phosphate fluoride application on early artificial carious lesions. Am J Dent. 2003; 16:91-5.

39. Eronat C, Eronat N, Alpoz AR. Fluoride uptake by enamel in vitro following application of various topical fluoride preparations. J Clin Pediatr Dent. 1993; 17(4):227-30.

40. Delbem AC, Cury JA. Effect of application time of APF and NaF gels on microhardness and fluoride uptake of in vitro enamel caries. Am J Dent. 2002; 15(3):169-72.

41. Bodde HE, Nelson DG, Koops PG, Arends J. Influence of repeated APF applications on long-term remineralization of initial lesions in bovine enamel. J Dent Res. 1985; 64(1):12-8.

42. Kim YS, Kwon H, Kim BI. Effect of nanocarbonate apatite to prevent re-stains after dental bleaching in vitro. J Dent.2011; 39(9):636-42. 
